\title{
Global inequality: A multidimensional perspective
}

\author{
Koen Decancq*
}

April 29, 2011

\begin{abstract}
This paper investigates the evolution of global well-being inequality between 1980 and 2010 based on three dimensions: income, health and education. The inequality of each of these dimensions shows a different pattern over time. To make an overall assessment of the evolution of well-being inequality, I make use of a recently developed multidimensional inequality index which reflects the implicit value judgments of the revised Human Development Index. Multidimensional well-being inequality has decreased over the considered period. However, this result is shown to depend crucially on the weighting scheme selected, the aggregation procedure and the transformation of the income dimension.
\end{abstract}

Keywords: global inequality, Gini coefficient, human development index, multidimensional inequality

JEL Classification: D63, I31, O52.

${ }^{*}$ Koen Decancq: Center for Economic Studies, Katholieke Universiteit Leuven, Naamsestraat 69, B3000 Leuven, Belgium and CORE, Université Catholique de Louvain, B-1348 Louvain-la-Neuve, Belgium. E-mail: koen.decancq@econ.kuleuven.be.

I thank the participants of the HDR 2010 consultation in Rabat and the "Scientific Interdisciplinary Seminar" of the University of Antwerp for their comments and remarks. I am grateful to my coauthors of related papers: Kristof Bosmans, André Decoster, María Ana Lugo, Erwin Ooghe and Erik Schokkaert for the numerous conversations we had on this topic. I am particularly indebted to María Ana Lugo for her detailed comments on an earlier draft. Remaining errors are all mine. 


\section{Introduction}

Is the world a more unequal place than 30 years ago? In the past few years, we have seen an animated debate emerging on whether global inequality has risen or, instead, declined rapidly. ${ }^{1}$ The controversy has been fueled by at least two differences of opinion. First, studies differ in the way they approximate missing data. Ideally, a study of global inequality is based on comparable micro data for all countries of the world. In absence of these data, some (heroic) assumptions on the approximation of missing data are inevitable. On top of that, the exercise of measuring inequality has an important normative component. Differences in value judgements on the notion of inequality and its measurement have been shown to result in different trends of global inequality.

What most authors seem to agree on is the appropriate "currency of inequality". Studies of global inequality focus almost without exception on one single dimension of human well-being, that is income. This implicit identification of global inequality with global income inequality might come as a surprise for the reader who is familiar with the writings of political philosophers such as Rawls (1971); Sen (1985) and Nussbaum (2000). They argue against a narrow-sided view of well-being that ignores various sources of heterogeneity with respect to other dimensions of life such as health and education. This broader perspective of well-being has, in recent years, influenced both academics and policy makers (Stiglitz, Sen, and Fitoussi, 2009). Yet, this multidimensional perspective seems to trickle only slowly in the literature on global inequality. ${ }^{2}$

In this paper I study the evolution of global inequality of well-being, where information on health and education, as well as income, are taken into consideration. In a series of recent papers, Ravallion (2010a,b, 2011) makes the distinction between two approaches to include the multiple dimensions of well-being in the analysis: a dimensionby-dimension approach, resulting in "large and eclectic dashboard" (Stiglitz, Sen, and Fitoussi, 2009, p.62) and a multidimensional approach which makes use of some aggregate index of well-being, to which Ravallion refers as a "mashup index of development". In the second section of this paper I will study the evolution of global inequality dimension by dimension. ${ }^{3}$ Such an approach clearly goes beyond a single focus on incomes and

\footnotetext{
${ }^{1}$ See, for instance, Chotikapanich, Valenzuela, and Rao (1997); Bourguignon and Morrisson (2002); Milanovic (2002, 2005); Capéau and Decoster (2005); Dowrick and Akmal (2005); Sala-I-Martin (2006); Pinkovskiy and Sala-I-Martin (2009); Atkinson and Brandolini (2010); Deaton (2010); Bosmans, Decancq, and Decoster (2011). Anand and Segal (2008) provide a comprehensive survey.

${ }^{2}$ Some recent exceptions of multidimensional studies on global inequalities are by Decancq, Decoster, and Schokkaert (2009); Decancq and Ooghe (2010); Herrero, Martínez, and Villar (2010); Muller and Trannoy (2011).

${ }^{3}$ The most well-known example of an dimension-by-dimension dashboard evaluation of global wellbeing is by the United Nations' Millenium Development Goals. Specific examples with a focus on the inequality within multiple dimensions of well-being are by Slottje, Scully, Hirschberg, and Hayes (1991); Hicks (1997); Easterlin (2000); Hobijn and Franses (2001); Neumayer (2003); World Bank (2005); United Nations Development Programme (2010).
} 
provides additional and even surprising insights. Unfortunately, such an approach does not lead to an overall appraisal of global inequality. ${ }^{4}$ More fundamentally, a dimensionby-dimension dashboard approach leads us to ignore the interrelationships and possible correlations between the dimensions of well-being. A world where one country is topranked in all dimensions, another second-ranked, and so on, is arguably more unequal than a world with the same distributional profiles in each dimension but where some countries are top-ranked in some dimensions, and other countries in others. Yet, according to a dimension-by-dimension approach, both situations are, by construction, assessed as "equally unequal". It is for this reason that I study, in section three, the evolution of global inequality by making use of one of the newly developed indices of multidimensional inequality. Given the popularity of the Gini coefficient in one-dimensional empirical work, I make use of a multidimensional extension of the Gini coefficient, which has recently been proposed by Decancq and Lugo (2011).

A multidimensional approach necessitates an explicit choice on standardization of variables, weighting of dimensions and a procedure to aggregate across the dimension. In this paper, I take as benchmark the choices implicit in the revised Human Development Index (HDI) which incorporates, along with per capita GDP, two non-monetary aspects of life (health and educational achievements). After a wide consultation process, the UNDP revisited in 2010 its methodology to compute the HDI. The main difference between the new index and the previous one is in the aggregation procedure (multiplicative rather than additive) and in the indicator of educational achievements (mean and expected years of schooling instead of literacy and enrolment rates). I use the most recent available data from the Human Development Report on population sizes, on Gross National Income (GNI) per capita, life expectancy and years of schooling for 86 countries in the period 1980-2010. ${ }^{5}$

The analysis is performed at the country level, rather than at the household or individual level, due to data limitations. This means that within-country inequality is ignored. This crude simplification of global well-being distribution makes us blind to important social trends such as, for instance, the increasing inequality in China. Unfortunately, very few data is available on within-country joint distributions of well-being for developed countries and a fortiori for developing countries. All the analyses are performed both weighting and not weighting by the population size of each country. In line with the existing literature on global income inequality, I refer to the unweighted

\footnotetext{
${ }^{4}$ Ravallion (2011) considers this to be an advantage, rather than a drawback of a dimension-bydimension dashboard approach. He writes "Imagine you go for your annual medical checkup. Your doctor does all the usual tests, but tells you that she will base her assessment solely on a single composite index - rescaling and averaging all the test results. You would be well advised to get a new doctor!"

${ }^{5}$ Data are downloaded from the UNDP web site (http://hdr.undp.org/en/media/HDI-trends-19802010.xls) in March 2011. See Human Development Report 2010 for more details. Appendix A lists the countries included in the analysis. Only countries for which the data for all variables in all years are available are included.
} 
estimates of inequality as "concept 1 inequality" and to the population-weighted results as "concept 2 inequality". Milanovic (2005) interprets concept 1 inequality as the inequality within the general assembly of the United Nations, where every country has one vote, irrespective of its size. One may find it unattractive to give the same weight to large populated countries (such as China) as to small countries (such as Luxembourg). Therefore I also provide population-weighted results.

The present analysis extends that of Decancq, Decoster, and Schokkaert (2009) in three ways: First, the multidimensional inequality index used in this paper extends the popular Gini coefficient, rather than the inequality index proposed by Atkinson (1970). To the best of my knowledge, this study is the first to use a multidimensional Gini coefficient to analyze the trend of global well-being inequality. Second, it uses more recent data, which allows to study the impact of the financial crisis on the inequality within the monetary dimension of well-being. Finally, the multidimensional framework is adjusted to take the revised methodology of the HDI as benchmark. This offers additional insights in the importance of the recent adjustments of the HDI methodology.

\section{Dimension-by-dimension analysis}

This section focuses on three dimensions of well-being: income, health and schooling. It presents a dimension-by-dimension analysis of the evolution of global well-being inequality.

\subsection{Global income inequality}

The literature on global inequality focused its attention almost exclusively on global income inequality. I take as the variable of interest here the Gross National Income (GNI) per capita expressed in 2008 dollars, corrected using the standard PPPs. Figure 1 presents the evolution of global income inequality since 1980. I present results for unweighted and weighted inequality (the left and right panel respectively). In each panel, the evolution for two degrees of bottom sensitivity is depicted. When the bottom sensitivity parameter $\delta$ equals 2 the Gini coefficient is obtained. For larger values of $\delta$ more weight is given to the bottom of the distribution. To ease comparison, the results are normalized such that $1980=100 .^{6}$

My findings are in line with the literature (Milanovic, 2005). Unweighted income inequality increases during the first two decades, reaches its peak around 2000 and declines afterwards, with a steeper decline for the Gini coefficient compared to the more bottomsensitive index. The drop of the Gini coefficient around 2008 is particularly remarkable.

\footnotetext{
${ }^{6}$ To be precise, I compute the one-dimensional s-Gini coefficient as characterized by Weymark (1981), using the Stata command SGINI, developed by Philippe Van Kerm. For the computations of the next section, a multidimensional extension of SGINI is used, which is available upon request from the author.
} 


\section{Global Income Inequality}
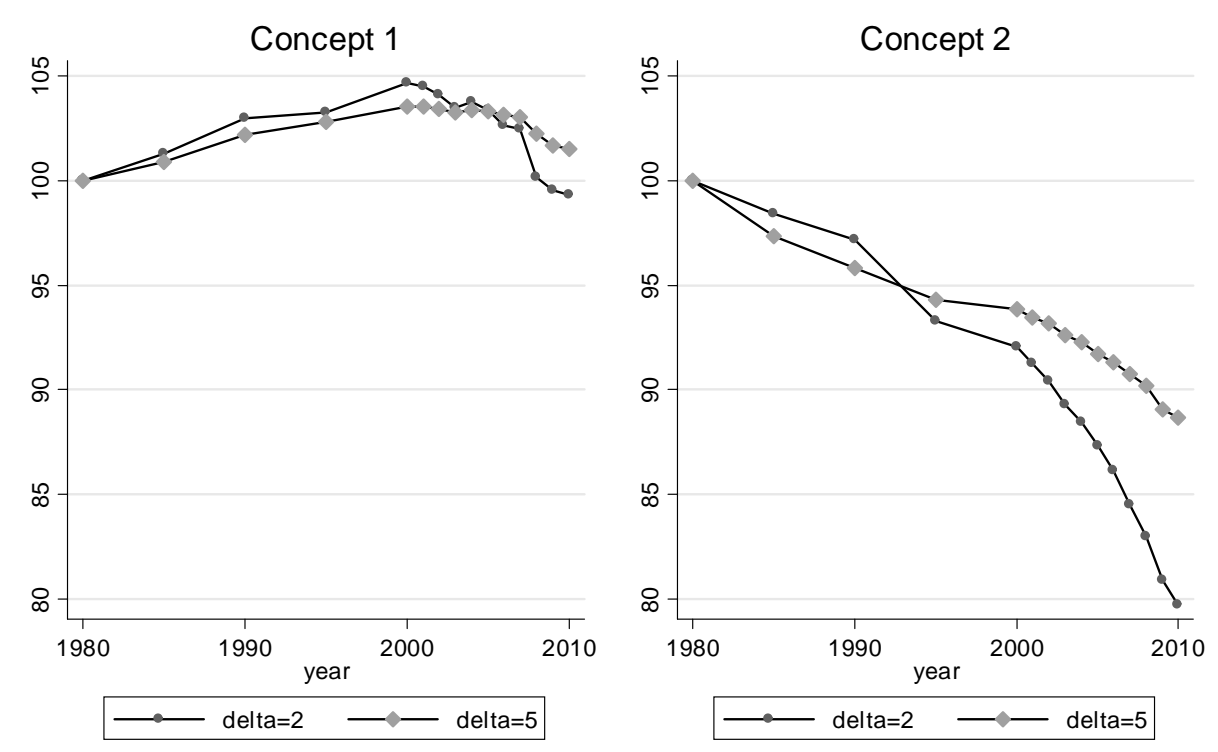

Source: Own calculations based on data from the HDR (March 2011)

Figure 1: Global inequality in GNI per capita for concept 1 and concept 2.

The financial crisis seems to have more than proportionally affected the richer countries. ${ }^{7}$

Population-weighted inequality declines steadily over the considered period: the Gini coefficient goes down by almost 20 per cent over the last three decades. This remarkable difference in pattern between concept 1 and 2 caused some additional controversy in the literature on global income inequality, with echoes in the popular press (The Economist, 2003). The reason for these diverging stories lies in the exceptional growth performance of China and India since 1980, and especially since 1990, together with the fact that these two countries account for such a big share of the world's population. In a counterfactual world without China and India, also population-weighted inequality would have increased with about 10 per cent.

\subsection{Global health inequality}

Recent studies of happiness and subjective life satisfaction have highlighted the large importance that people give to health when judging their overall well-being. ${ }^{8}$ Life ex-

\footnotetext{
${ }^{7}$ Note that here, as in the rest of the paper, a relative perspective on inequality is taken, this means that equal proportional increases of all incomes do not affect inequality. This is a common assumption in global inequality, but a debatable one. Atkinson and Brandolini (2004, 2010); Bosmans, Decancq, and Decoster (2011) show that an equally justifiable absolute perspective, where equal absolute increases do not affect inequality, leads to a less rosy picture on global inequality.

${ }^{8}$ For some recent references to the booming literature on happiness and subjective well-being see Layard (2005); Clark, Frijters, and Shields (2008) and the many references therein.
} 
pectancy at birth is the most widely used measure of health achievements. This indicator is not without objections, as it focuses solely on expected length of life at birth and omits any consideration on the quality of that life.

Since it is relatively easier to increase an extra expected year of life in a country with low initial health performance -say, Botswana- compared to a country on the frontier of medical knowledge -say, Japan- one may expect a rapid decline of health inequality over the last three decades. Indeed, in 2005 the UNDP seemed quite optimistic about the evolution of life expectancy and its inequality:

"In a little more than a decade average life expectancy in developing countries has increased by two years. On this indicator human development is converging: poor countries are catching up with rich ones." (Human Development Report, 2005)

Unfortunately, this claim is not supported by the computations for concept 1 inequality nor by recent findings in the literature on global health inequality. ${ }^{9}$ In figure 2 , the evolution of health inequality is shown, measured by the same two indices of inequality. The unweighted inequality index shows a steadily increase during the early 1990's, particularly for the more sensitive to the bottom index $\delta=5$. This fact can be largely attributed to the devastating effect of the HIV/AIDS epidemic in many Sub-Saharan countries. As an example of the magnitude of the effect of HIV/AIDS on a country's health outcomes, life expectancy in Botswana went from 64 years in 1990 to 49 years a decade later. The global trend is reversed only in the first years of the new century.

A substantially different pattern emerges when one weighs the distribution by the countries population sizes. Since 1980, inequality in life expectancy has been declining uninterruptedly (right panel of figure 2). The differences in the two graphs reflects the spectacular improvement in health performance of the more populated countries such as Bangladesh and Indonesia (19 and 17 additional years between 1980 and 2010) and, to the lower but equally impressive achievements in India, China and Brazil (10 to 8 additional expected years of life).

\subsection{Global educational inequality}

In 2010, during the revision of the HDI-methodology, the UNDP opted for "years of schooling" as the new indicator of educational achievement, replacing the combined literacy and enrolment rate previously used. These newly chosen variables have the advantage of being less artificially bounded from above compared to the literacy and enrolment rates which reached their physical limit of 100 per cent in almost all OECD countries. In

\footnotetext{
${ }^{9}$ See McMichael, McKee, Shkolnikov, and Valkonen (2004); Moser, Shkolnikov, and Leon (2005); Becker, Philipson, and Soares (2005); Decancq, Decoster, and Schokkaert (2009); Muller and Trannoy (2011).
} 

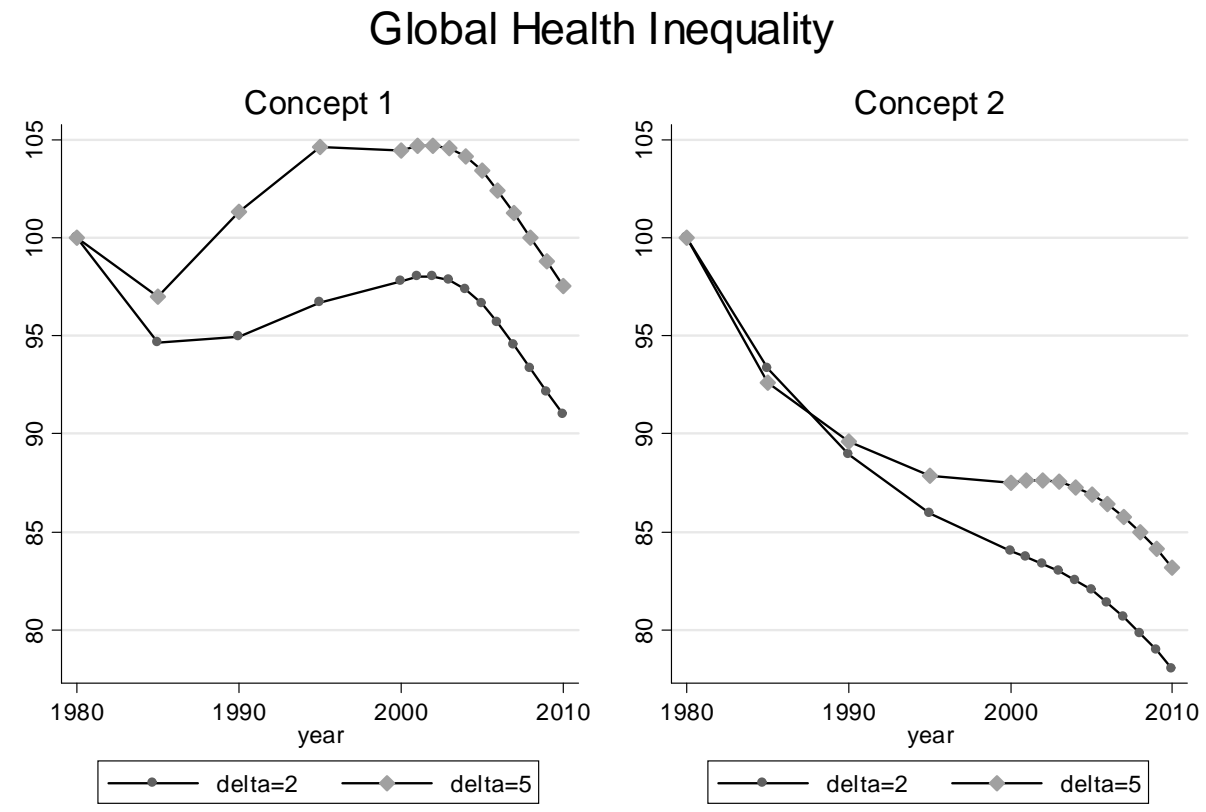

Source: Own calculations based on data from the HDR (March 2011)

Figure 2: Global inequality in life expectancy for concept 1 and concept 2.

the past, some authors have expressed their worries about an artificial convergence in the educational achievements due to the statistical artifact that the measurement apparatus was blind for further increases in the achievements of the top-performers (Neumayer, 2003; McGillivray and Ram Pillarisetti, 2004). The variable "years of schooling" is less susceptible to this worry. In this paper I follow the new HDI standard and consider inequality in a combined index capturing expected and mean years of schooling, similar to Hicks (1997).

Figure 3 shows a clear trend of declining educational inequality, both for weighted and unweighted inequality indices and for both degrees of bottom-sensitivity. This result reflects earlier findings with different educational indicators and different indices of inequality. In fact, one finds Lorenz dominance of the later years with respect to the earlier ones, so all inequality indices will agree that schooling inequality decreased over time.

In this section, we have summarized the inequality in three dimensions of the HDI. We have seen that they evolved quite differently in the past few decades. At this point it remains hard to make an unambiguous assessment of the trend of overall well-being inequality. To provide such an evaluation I take a multidimensional perspective in the next section. 

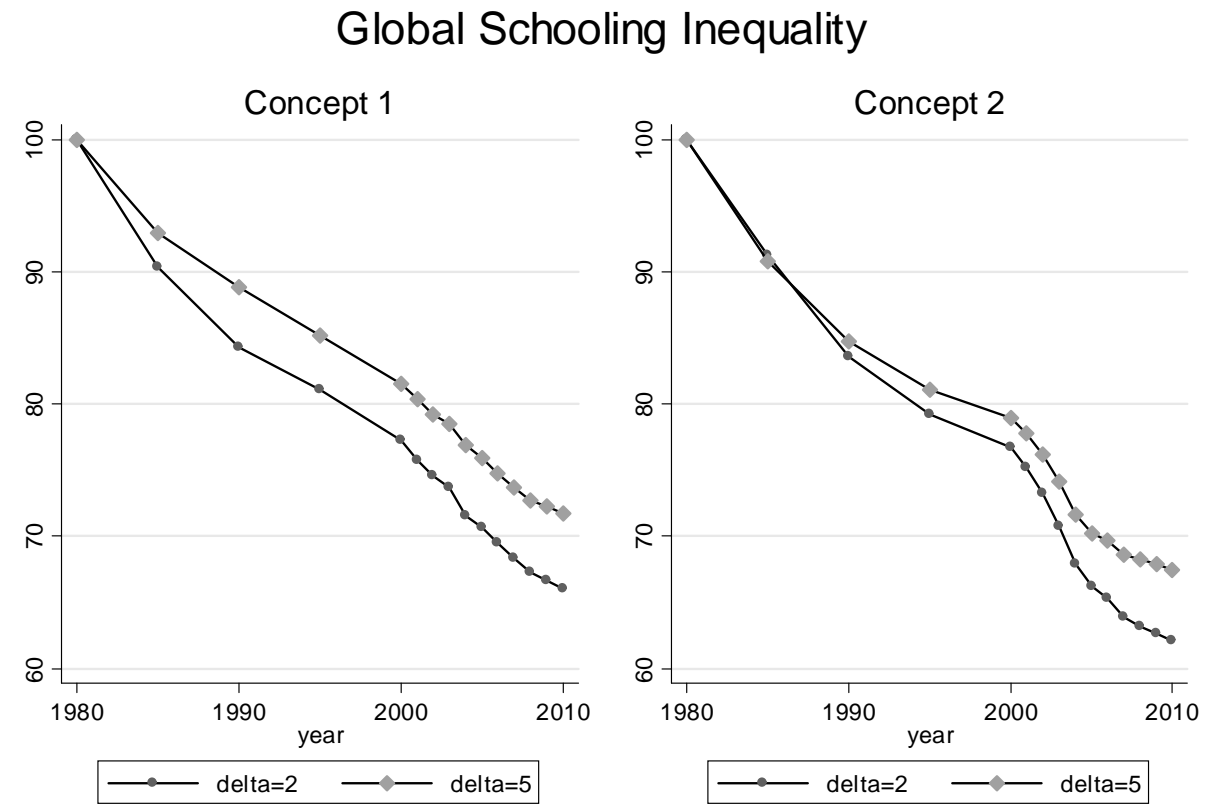

Source: Own calculations based on data from the HDR (March 2011)

Figure 3: Global inequality in years of schooling for concept 1 and concept 2.

\section{Multidimensional analysis}

Broadly speaking, two routes can be taken to evaluate multidimensional inequality. The first computes inequality in each dimension and then combines the dimension-specific inequality indices through some function, for instance a weighted sum. ${ }^{10}$ This two-step inequality index becomes - by construction - insensitive to the changes in correlation between the different dimensions of well-being. As described in the introduction, not being able to incorporate information on the correlation structure among dimensions of well-being represents an important limitation. Indeed, this is the main reason argued for moving beyond the dimension-by-dimension approach described above.

The second route, which is taken here, is the mirror-image of the two-step procedure previously described. First, for each country the three achievements in the dimensions of well-being are aggregated into a composite index of well-being. The HDI seems an obvious candidate for such a summary statistic of well-being. Second, I calculate the inequality using a multidimensional extension of the Gini index. The next paragraph considers these two steps in some detail.

\footnotetext{
${ }^{10}$ This is the route taken by the measure proposed by the HDR (2010, p.219) and in a theoretical contribution to the derivation of a multidimensional Gini index by Gajdos and Weymark (2005).
} 


\subsection{Method}

In the first step, the attainments in the different dimensions of well-being are aggregated. In order to do this, three essential decisions have to be made. First, a standardization procedure needs to be chosen to make the measurement units of the dimensions comparable. Income is generally expressed in monetary units, such as US\$ whereas life expectancy and years of schooling are measured in years. For the benchmark analysis, I will use the same transformation as the revised HDI (2010, p. 217). That is,

$$
\text { Dimension index }=\frac{\text { actual value }- \text { minimum value }}{\text { maximum value }- \text { minimum value }} \text {. }
$$

The "maximum values" are set to the observed maximum values among the countries in the time series. The "minimum values" are conceived as the subsistence values. The exact values can be found in Appendix B. For income, an additional transformation is made: the GNI per capita is transformed using a logarithmic transformation. The concavity of the logarithmic transformation reflects the diminishing returns of the conversion of income into well-being (Anand and Sen, 2000). Afterwards, I will investigate the impact of this specific choice on the results.

Second, the specific functional form has to be selected to aggregate these transformed dimensions. After the 2010 revision of the HDI-methodology, the UNDP has chosen the geometric or multiplicative average:

$$
H D I^{\text {new }}=\left(I_{\text {Life }}\right)^{1 / 3} \times\left(I_{\text {Education }}\right)^{1 / 3} \times\left(I_{\text {Income }}\right)^{1 / 3} .
$$

The multiplicative average has the advantage of limiting the degree of substitutability among dimensions (HDR 2010, p. 15). In contrast, the previous aggregation function used was a linear average implying perfect substitutability across dimension indices.

$$
H D I^{\text {old }}=1 / 3\left(I_{\text {Life }}\right)+1 / 3\left(I_{\text {Education }}\right)+1 / 3\left(I_{\text {Income }}\right) .
$$

The new aggregation procedure does, indeed, put a limit to the substitutability, but it does so in a very specific way. In particular, the elasticity of substitution between all pairs of dimensions is set equal to one. As before, I will use the HDI choice of aggregation for the benchmark computations, and later investigate the impact of this choice.

Finally, weights have to be assigned to each dimension used in the aggregation. Dimension-weights are important in determining the trade-offs between the different dimensions of well-being. Fixing these trade-offs is a difficult matter. How much additional income is necessary to compensate for a loss in one year of life expectancy? In this question there is an echo of the everlasting philosophical inquiries about the nature of "a good life" (Decancq and Lugo, 2012). Once again, I follow the choice embedded in the revised HDI - equal weights - for the benchmark analysis (reflected by the $1 / 3$ in expression (1) and (2)) . 


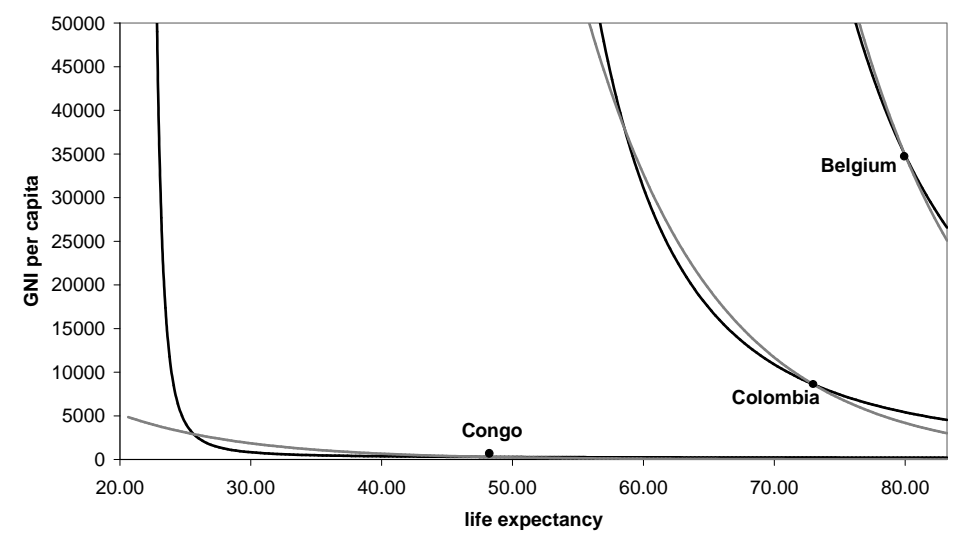

Figure 4: Iso-Human Development curves for the revised HDI (black) and the old HDI (gray) between life expectancy and GNI per capita for Congo, Colombia and Belgium.

The choices made by the HDR 2010 on standardization, aggregation and weighting reflect one particular view on how an appropriate well-being index should be constructed. To crystallize the implied trade-offs of the revised HDI, I depict in Figure 4 the iso-human development curves between life expectancy and GNI per capita for Congo, Colombia and Belgium. The black curves represent the implied trade-offs of the revised HDI, whereas the gray curves do the same for a linear aggregation (thereby approximating the old HDI). After inspecting Figure 4, one may find the trade-offs of the revised HDI debatable or even troublesome (Ravallion, 2010b). In particular the limited responsiveness of the HDI to increases in the Congolese life expectancy seems contentious.

In the second step, the inequality among the well-being indices obtained in the first step is computed. I use an extension of the Gini coefficient proposed by Decancq and Lugo (2011), where an extensive treatment of the properties of the index is given as well as an application to Russian micro data. Here I limit myself to a non-technical treatment of two essential properties of the index, which - I argue - capture the multidimensional nature of the approach to inequality.

The first desired characteristic of a multidimensional index of inequality is that the index should decrease after a multidimensional averaging procedure. ${ }^{11}$ An example might help to clarify. Let us compare a stylized world in two moments in time: $T_{0}$ and $T_{1}$. In each situation there are two countries (rows) and three dimensions of well-being (columns).

\footnotetext{
${ }^{11}$ An averaging procedure is a pre-multiplication with a bistochastic matrix, see Kolm (1977); Weymark (2006) for more details.
} 


$$
T_{0}=\left[\begin{array}{lll}
10 & 80 & 30 \\
90 & 20 & 70
\end{array}\right] \text { and } T_{1}=\left[\begin{array}{ccc}
30 & 65 & 40 \\
70 & 35 & 60
\end{array}\right]
$$

In each dimension, the worst performing country has improved its situation by the same amount as the best performing country worsened his. The averaging property will require that the world be considered more equal after the change, that is in situation $T_{1}$. This captures one of the possible extensions of the Pigou-Dalton transfer principle into the multidimensional setting, which states that a transfer from a better-off to a worse-off individual should decrease inequality. ${ }^{12}$

The second property involves an aversion to correlation between the dimensions. ${ }^{13}$ Let us now compare the world in the following points in time: $T_{0}$ and $T_{2}$.

$$
T_{0}=\left[\begin{array}{lll}
10 & 80 & 30 \\
90 & 20 & 70
\end{array}\right] \text { and } T_{2}=\left[\begin{array}{ccc}
10 & 20 & 30 \\
90 & 80 & 70
\end{array}\right]
$$

In period $T_{2}$ the first country is bottom-ranked in all dimensions and the second country is top-ranked in all dimensions, whereas the performance was much more mixed in $T_{0}$. Note, however, that the inequality within each dimension remains unchanged. The reader might agree that the world is a more equal place in situation $T_{0}$ where the countries have a more mixed performance across the different dimensions.

In interplay with other attractive properties, a multidimensional inequality index can be obtained which satisfies the above essential properties under some restrictions on the parameter choices (Decancq and Lugo, 2011).

\subsection{Benchmark result}

The analysis of multidimensional inequality begins with a well-being index which coincides with the revised HDI. This will be referred to as the benchmark result in the rest of the paper. One might consider the choices on standardization, aggregation and weighting embedded in the HDI rather arbitrary and even unattractive. Therefore in the next section a stress-test of the benchmark result is performed by investigating the

\footnotetext{
${ }^{12} \mathrm{An}$ alternative approach is to investigate the one-dimensional inequality in some composite index of well-being and (for example McGillivray and Ram Pillarisetti (2004); Becker, Philipson, and Soares (2005); Noorbakhsh (2007); Wolff, Chong, and Auffhammer (2010)). The difference with the approach taken here is whether a one-dimensional transfer principle is imposed or a multidimensional one. See Decancq, Decoster, and Schokkaert (2009) for more details.

${ }^{13}$ The notion of correlation-sensitivity has been introduced in the literature on multidimensional inequality by Atkinson and Bourguignon (1982). Dardanoni (1996) uses a similar approach to correlation aversion as the one introduced here. Pogge (2009) writes "a credible index of development must be sensitive to whether an increase in literacy goes to landowners or the landless, an improvement in medical care goes to children or to the aged, an increase in enrolment to privileged university students or to children in slums, an increase in life expectancy to the elite or to the marginalized, enhanced physical security to males or to females."
} 

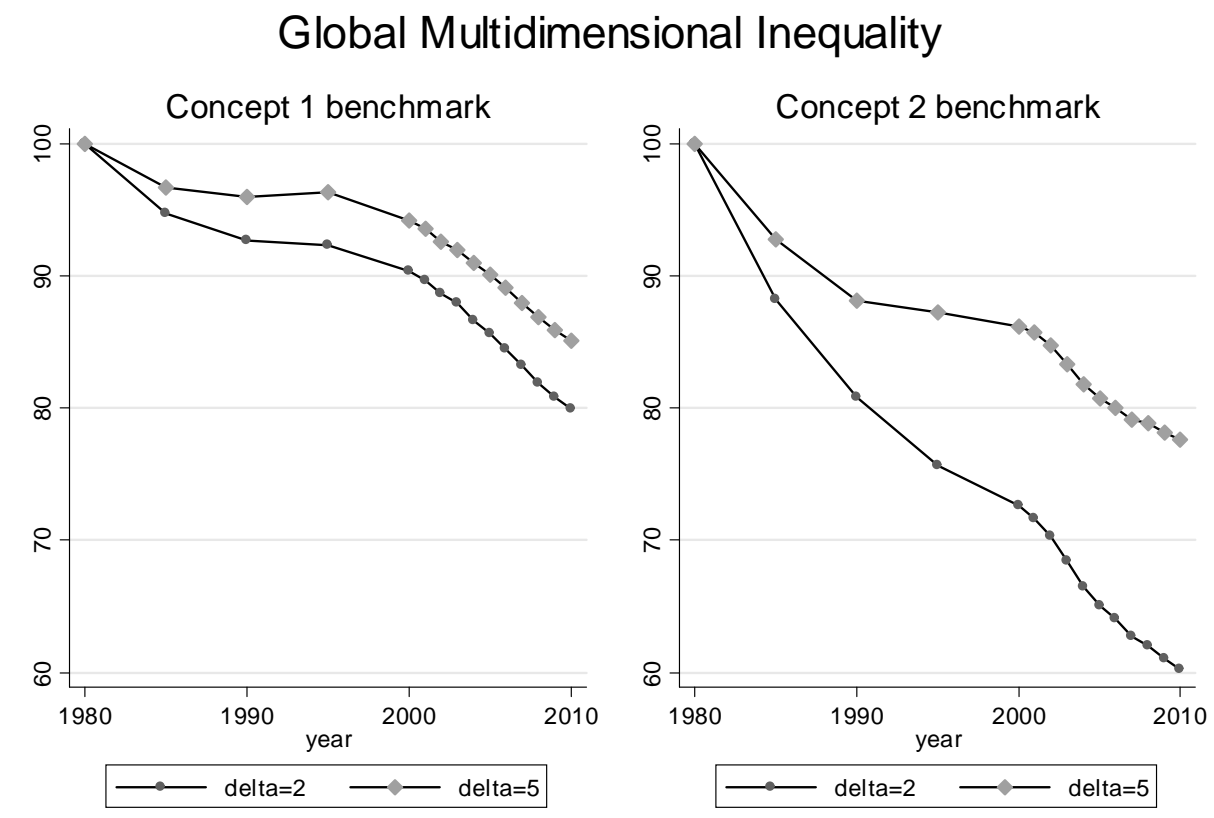

Source: Own calculations based on data from the HDR (March 2011)

Figure 5: Global multidimensional inequality (benchmark) for concept 1 and concept 2.

robustness of the obtained trend in multidimensional inequality for alternative - a priori equally justifiable - choices.

Figure 5 provides the evolution of multidimensional global inequality for the benchmark case. The finding of decreasing inequality is in line with the earlier findings of Decancq, Decoster, and Schokkaert (2009), who find a similar pattern in their analysis. Furthermore, this pattern confirms to a large extent a conjecture expressed by the HDR 2005:

"For most of the past 40 years human capabilities have been gradually converging. From a low base, developing countries as a group have been catching up with rich countries in such areas as life expectancy, child mortality, and literacy. A worrying aspect of human development today is that overall state of converging is slowing - and for a large group of countries divergence is becoming the order of the day." (Human Development Report, 2005).

In fact, the worry of the HDR 2005 about a slowing convergence during the last decade of the previous century seems to be overcome after 2000, resulting in a steady decline of global multidimensional inequality between 2000-2010. Even though inequality declines over time, the absolute level remains high. The welfare losses due to well-being 
inequality range from 20 up to 50 per cent depending on the adhered bottom-sensitivity. That means that an ethical observer could discard between 20 per cent and 50 per cent of total income, health and educational achievements, with social indifference if he could freely equalize income, health and education across countries.

\subsection{Robustness analysis}

In this section, I study the robustness of the above benchmark result for alternative choices on the weights and on aggregation and standardization procedures. ${ }^{14}$

Let's first study the impact of the weights, by considering one specific alternative weighting scheme. I follow Bourguignon and Morrisson (2002); Becker, Philipson, and Soares (2005) and consider a notion of well-being where educational achievement is not seen as an independent component of well-being, but rather as an aspect with only instrumental value. This is done by setting the weight of education equal to zero. The result of this alternative choice is captured by Figure 6. Unweighted multidimensional inequality increases in the first half of the considered period and then reverts to its initial level. Population-weighted estimates are much less sensitive to the choice of this alternative weighting scheme, especially when the bottom sensitivity parameter takes moderate values ( $\delta$ equal to 2 , for instance). Of course, this weighting scheme reflects only one very specific alternative to equal weighting across the three dimensions of the HDI. Studying more alternative weighting schemes goes beyond the scope of this paper, but the reader is referred to Decancq and Ooghe (2010) for a more systematic study of the impact of the weighting scheme to the results on global inequality and welfare.

Second, the benchmark results are compared to an alternative based on a different aggregation procedure. First, I compute the evolution of well-being inequality with a linear aggregation procedure as captured by expression (2). By doing so, I revert to the aggregation formula which had been used by the UNDP between 1990 and 2010. The result is very similar to the multiplicative aggregation and therefore not shown in the paper. Instead in Figure 7, I provide an alternative which takes for each country its worst performance across the three dimensions as well-being index. A similar proposal can be found in Lorzano Segura and Gutierrez Moya (2009). Such an approach favors countries with an equal human development across the three dimensions of well-being. This alternative excludes substitutability between the dimensions, which seems in line with the writings of the Human Development Report. It leads to increasing unweighted inequality up to 2000 and a declining trend afterwards.

Finally, I look at the impact of the standardization procedure chosen by the UNDP. As an alternative I return to the benchmark results, without applying the logarithmic

\footnotetext{
${ }^{14}$ A robustness analysis for the impact of measurement error and data selection rules falls outside the scope of this paper. See Wolff, Chong, and Auffhammer (2010) for an analysis of the imprecision of the HDI due to measurement error. The authors obtain large estimates of imprecision ranging up to 0.11 for a country as Niger (on a scale between 0 and 1).
} 

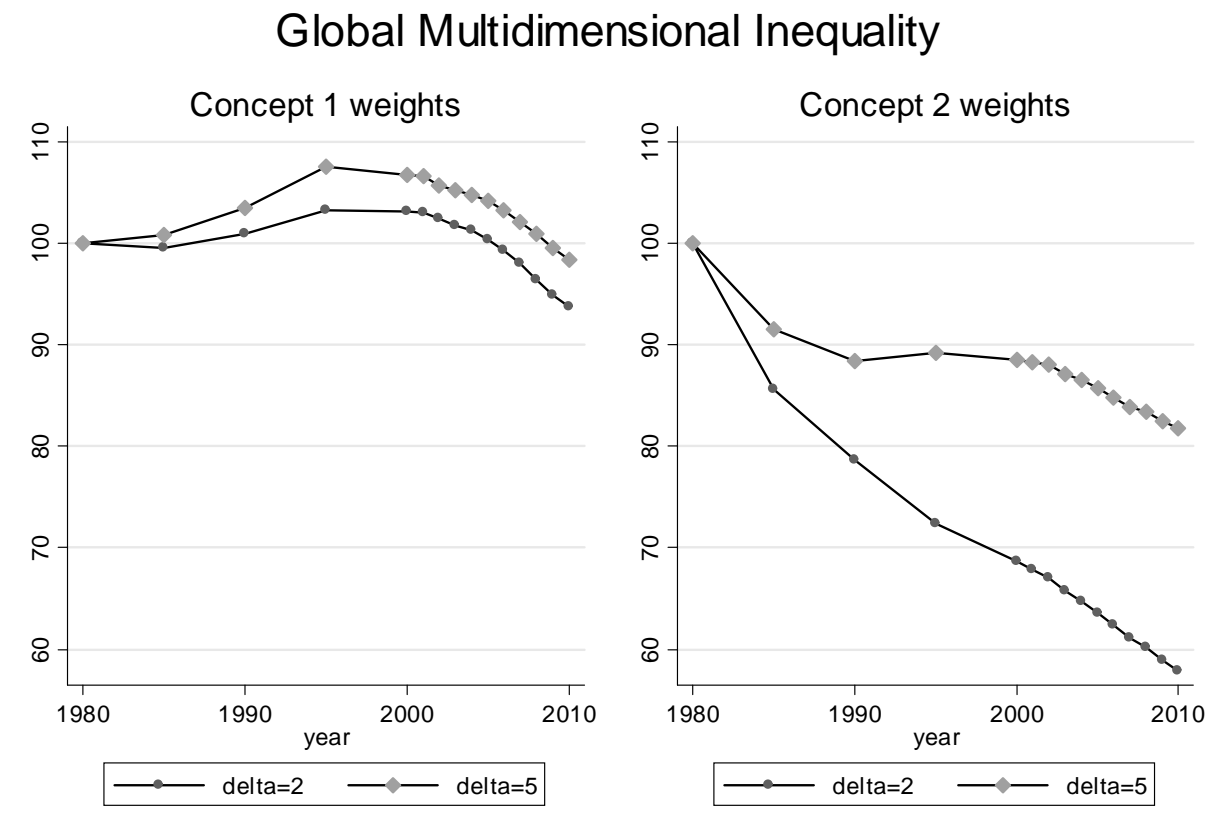

Source: Own calculations based on data from the HDR (March 2011)

Figure 6: Global multidimensional inequality (adjusted dimension weights) for concept 1 and concept 2 .

transformation of the monetary dimension. After adjusting the income maximal and minimal values accordingly, GNI per capita is used directly, rather than first taking the logarithm of GNI per capita. Such an approach reflects the common practice in the multidimensional literature on welfare and inequality measurement.Figure 8 shows the evolution of well-being inequality when no logarithmic transformation is taken. Unweighted inequality increases slowly over time, reaches its peak around 2000 and decreases afterwards (with a little dip in 2008 due to the outbreak of the financial crisis). On the contrary, population-weighted inequality decreases over time, even after removal of the logarithmic transformation.

To summarize, the benchmark inequality computation which reflects the particular value judgements present in the HDI presents a relatively rosy picture of decreasing inequality, both in the population weighted and unweighted case. The limited robustness analysis has shown, however, that for the unweighted case, this rosy picture crucially depends on these value judgements on weighting, aggregation and standardization. Alternatively, equally justifiable choices in these domains may lead to an increasing unweighted global inequality instead. 


\section{Global Multidimensional Inequality}
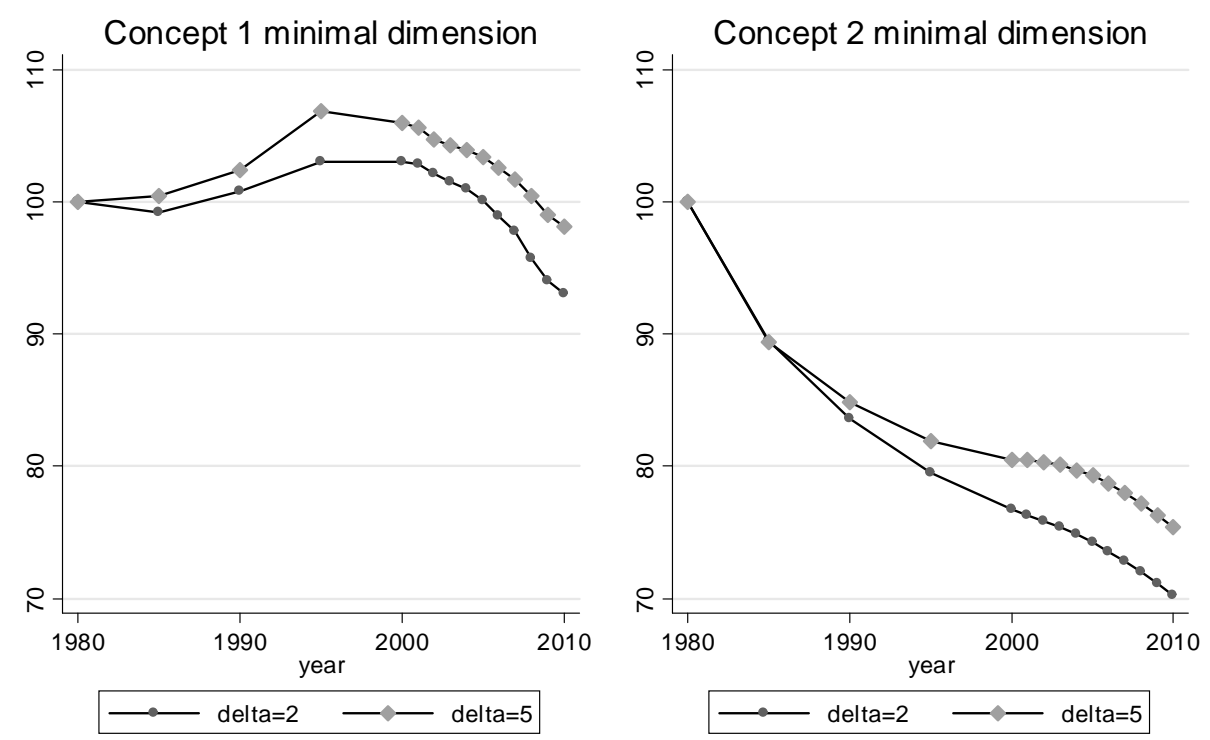

Source: Own calculations based on data from the HDR (March 2011)

Figure 7: Global multidimensional inequality (adjusted aggregation procedure) for concept 1 and concept 2 .

\section{Conclusion}

In this paper, the evolution of world inequality is studied while taking the argument that well-being is a multidimensional notion seriously. As a starting point, I have studied the evolution of inequality within the three dimensions of the HDI separately. The evolution of global income inequality is remarkably different when taking a population unweighted or population weighted perspective. Unweighted health inequality showed an increase during the 1990s while educational inequality declined throughout the considered period 1980-2010. Unfortunately, this dimension-by-dimension approach is unable to take into account the correlation structure between the dimensions of well-being. Therefore I adopted a second explicitly multidimensional approach by using the newly developed extension of the Gini coefficient proposed by Decancq and Lugo (2011). Multidimensional inequality shows a declining pattern, but this pattern seems sensitive to the particular perspective on the weights, aggregation procedure and transformation taken, especially when no population weights are used. Giving less weight to the educational dimension, moving towards a more severe aggregation procedure or dropping the logarithmic transformation of incomes, leads to an increase of unweighted global inequality during the 1990's rather than a decrease. This finding illustrates once more that the normative choices on appropriate bottom-sensitivity, population-weighting, aggregation, standard- 

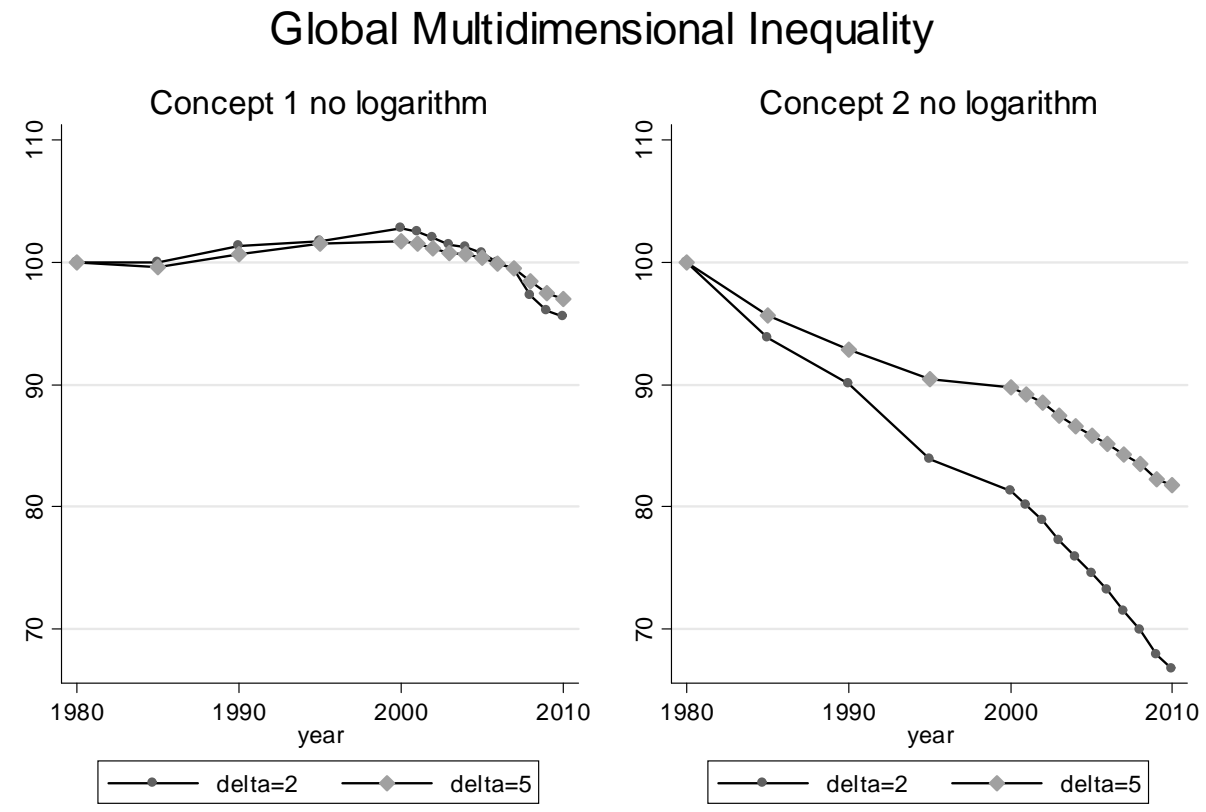

Source: Own calculations based on data from the HDR (March 2011)

Figure 8: Global multidimensional inequality (adjusted transformation) for concept 1 and concept 2 .

ization and weighting of the dimensions have a potentially large impact on the empirical results. More theoretical insights into how these parameter choices can and should be made, are needed.

Two directions for further research are identified. First, given the recent changes of the well-being distribution within countries (for instance, the rapid changes within the Chinese society) it is an interesting questions to measure global well-being inequality on the micro-level. Arguably heavy parametric assumptions on the different distributions and their correlation structure are inevitable. The data collected for the recently proposed multidimensional human poverty index by Alkire and Santos (2010) and by HDR (2010) can serve as a starting point for such an analysis.

Finally, though I believe that understanding the evolution of global inequality is a relevant question, it remains a condition sine qua non for the more fundamental inquiries about the underlying sources of these changes. Why is the world such an unequal place? What are the driving forces for the changing global inequality? What is the role of globalization? What is the impact of demographic changes? How important is the impact of calamities such as the HIV/AIDS epidemic and the financial crisis? A systematic study of these questions based on counterfactual scenarios can be helpful to quantify the relative magnitudes of the different sources of global well-being inequality. 


\section{Appendix A. Countries in the data set}

The Human Development Report (2010) data base contains data for 194 countries. An arguably strict data selection rule is applied: only countries for which I have all data in all periods are included in the analysis, which reduces the data set to 86 countries. Table 1 gives an overview. This reduced data set contains 77 per cent of the 2010 population. Most missing observations are due to missing schooling data. A procedure with interpolation or extrapolation of schooling data leads to a coverage of 116 countries with qualitatively the same results on global inequality as the ones I have presented here.

Table 1: Countries in the data set

\begin{tabular}{|c|c|c|c|}
\hline Algeria & Ecuador & Kenya & Peru \\
\hline Argentina & Egypt & Korea & Philippines \\
\hline Australia & Fiji & Latvia & Portugal \\
\hline Austria & Finland & Lesotho & Rwanda \\
\hline Bangladesh & France & Luxembourg & Saudi Arabia \\
\hline Belgium & Gabon & Malawi & Senegal \\
\hline Benin & Ghana & Malaysia & Sierra Leone \\
\hline Botswana & Greece & Mali & Spain \\
\hline Bulgaria & Guatemala & Malta & Sudan \\
\hline Burundi & Guyana & Mauritius & Sweden \\
\hline Cameroon & Honduras & Mexico & Switzerland \\
\hline Canada & Hong Kong & Morocco & Thailand \\
\hline Central African Republic & Hungary & Mozambique & Togo \\
\hline Chile & Iceland & Nepal & Trinidad and Tobago \\
\hline China & India & Netherlands & Tunisia \\
\hline Colombia & Indonesia & New Zealand & Turkey \\
\hline Congo & Ireland & Nicaragua & United Kingdom \\
\hline Congo (Dem. Republ.) & Israel & Niger & United States \\
\hline Costa Rica & Italy & Norway & Venezuela \\
\hline Côte d'Ivoire & Jamaica & Pakistan & Zambia \\
\hline Cyprus & Japan & Panama & \\
\hline Denmark & Jordan & Paraguay & \\
\hline
\end{tabular}




\section{Appendix B. Technical notes}

A. The well-being index. Let the achievement of a country be described by a vector $x$ containing seven indicators: life expectancy at birth (Life); literacy rate (Lit); enrolment rate (Enrol); expected years of schooling (E.School); mean years of schooling (M.Schoool); gross domestic product per capita (GDP) and gross national product per capita (GNI). A broad class of well-being indices can be written as follows

$$
W(x)= \begin{cases}{\left[\sum_{j=1}^{7} w_{j} I_{j}\left(x_{j}\right)^{\beta}\right]^{1 / \beta}} & \text { for } \beta \neq 0 \\ \prod_{j=1}^{7} I_{j}\left(x_{j}\right)^{w_{j}} & \text { for } \beta=0 .\end{cases}
$$

Selecting a particular well-being index then boils down to setting the weights $w_{1}, \ldots, w_{7}$, the transformation functions $I_{j}$ and the aggregation procedure, captured by parameter $\beta$. The revised Human Development Index $\left(\mathrm{HDI}^{\text {new }}\right)$ and the old version $\left(\mathrm{HDI}^{\text {old }}\right)$ are special cases of this broad class of well-being indices. ${ }^{15}$ Table 2 summarizes the respective parameter choices, assuming that unconsidered dimensions get a weight of zero. The benchmark case of this paper considers $\mathrm{HDI}^{\text {new }}$. For the sensitivity analyses, the weight of E.School and M.School is first set equal to zero (while renormalizing the remaining weights to $1 / 2$ ), then I set $\beta=1$ and approximate $\beta=-\infty$ and finally I replace $I_{G N I}$ by $\left(x_{j}-\underline{x}_{j}\right) /\left(\bar{x}_{j}-\underline{x}_{j}\right)$.

Table 2: Parameter choices for old and new Human Development Index.

\begin{tabular}{l|llllll}
\hline & $\beta$ & $j$ & $w_{j}$ & $I_{j}$ & $\bar{x}_{j}$ & $\underline{x}_{j}$ \\
\hline \hline HDI $^{\text {old }}$ & 1 & Life & $1 / 3$ & $\left(x_{j}-\underline{x}_{j}\right) /\left(\bar{x}_{j}-\underline{x}_{j}\right)$ & 85 & 25 \\
& & Lit & $2 / 9$ & $\left(x_{j}-\underline{x}_{j}\right) /\left(\bar{x}_{j}-\underline{x}_{j}\right)$ & 100 & 0 \\
& & Enrol & $1 / 9$ & $\left(x_{j}-\underline{x}_{j}\right) /\left(\bar{x}_{j}-\underline{x}_{j}\right)$ & 100 & 0 \\
& & GDP & $1 / 3$ & $\left(\log \left(x_{j}\right)-\underline{x}_{j}\right) /\left(\bar{x}_{j}-\underline{x}_{j}\right)$ & $\log (40000)$ & $\log (100)$ \\
\hline HDI $^{\text {new }}$ & 0 & Life & $1 / 3$ & $\left(x_{j}-\underline{x}_{j}\right) /\left(\bar{x}_{j}-\underline{x}_{j}\right)$ & 83.2 & 20 \\
& & E.School & $1 / 6$ & $\left(x_{j}-\underline{x}_{j}\right) /\left(\bar{x}_{j}-\underline{x}_{j}\right)$ & 20.6 & 0 \\
& \multirow{2}{*}{ M.School } & $1 / 6$ & $\left(x_{j}-\underline{x}_{j}\right) /\left(\bar{x}_{j}-\underline{x}_{j}\right)$ & 13.2 & 0 \\
& & GNI & $1 / 3$ & $\left(\log \left(x_{j}\right)-\underline{x}_{j}\right) /\left(\bar{x}_{j}-\underline{x}_{j}\right)$ & $\log (108211)$ & $\log (163)$ \\
\hline
\end{tabular}

B. The multidimensional inequality index. If $X$ captures the achievement vectors $\left\{x^{1}, \ldots, x^{n}\right\}$ of the $n$ countries in the world, the well-being inequality is measured by

$$
I(X)=1-\sum_{i=1}^{n}\left[\left(\frac{r^{i}}{n}\right)^{\delta}-\left(\frac{r^{i}-1}{n}\right)^{\delta}\right] \frac{W\left(x^{i}\right)}{W(\mu)},
$$

\footnotetext{
${ }^{15}$ To be precise, the revised HDI proposed by the UNDP in 2010 equals $1.016888 \times H D I^{\text {new }}$ due to an additional renormalization of the educational composite indicator which consists of M.School and E.School.
} 
where $\mu$ is the achievement vector containing all dimension-wize means and $r^{i}$ is the rank of country $i$ on the basis of $W$. The parameter $\delta$ captures the bottom sensitivity. For more details, see Decancq and Lugo (2011).

\section{References}

Alkire, S., and M. E. Santos (2010): "Acute multidimensional poverty: a new index for developing countries," Discussion Paper 38, Oxford Poverty and Human Development Initiative.

Anand, S., and P. Segal (2008): "What do we know about global income inequality," Journal of Economic Literature, 46(1), 57-94.

Anand, S., And A. K. Sen (2000): "The income component of the Human Development Index.," Journal of Human Development, 1(1), 83-106.

Atkinson, A. B. (1970): "On the measurement of inequality," Journal of Economic Theory, 2(3), 244-263.

Atkinson, A. B., And F. Bourguignon (1982): "The comparison of multidimensioned distributions of economic status," The Review of Economic Studies, 49(2), $183-201$.

Atkinson, A. B., And A. Brandolini (2004): "Global inequality and poverty: Absolute, relative or intermediate?," Discussion paper, Mimeo.

(2010): "On Analyzing the World Distribution of Income," The World Bank Economic Review, 24(1), 1-37.

Becker, G. S., T. J. Philipson, and R. R. Soares (2005): "The quantity and quality of life and the evolution of world inequality," The American Economic Review, 95(1), 277-291.

Bosmans, K., K. Decancq, and A. Decoster (2011): "The evolution of global inequality: absolute, relative and intermediate views," Discussion paper, CES discussion paper 11.03 .

Bourguignon, F., And C. Morrisson (2002): "Inequality among world citizens: 1820 - 1992," The American Economic Review, 92(4), 727-744.

Capéau, B., and A. Decoster (2005): "The rise or fall of world inequality. A spurious controversy?," World Economic Papers, 166, 37-53. 
Chotikapanich, D., R. Valenzuela, and D. S. P. Rao (1997): "Global and Regional Inequality in the Distribution of Income: Estimation with Limited and Incomplete Data," Empirical Economics, 22(4), 533-46.

Clark, A. E., P. Frijters, and M. Shields (2008): "Relative income, happiness and utility: an explanation for the Easterlin paradox and other puzzles," Journal of Economic Literature, 46(1), 95-144.

Dardanoni, V. (1996): "On multidimensional inequality measurement," in Research on Economic Inequality, ed. by C. Dagum, and A. Lemmi, vol. 6, pp. 201-205. JAI Press, London.

Deaton, A. (2010): "Price indexes, inequality, and the measurement of world poverty," The American Economic Review, 100, 1-35.

Decancq, K., A. Decoster, and E. Schokkaert (2009): "The evolution of world inequality in well-being," World Development, 30(1), 11-25.

DeCAncQ, K., And M. A. Lugo (2011): "Inequality of well-being: A multidimensional approach," Economica (forthcoming).

(2012): "Weights in multidimensional indices of well-being: An overview," Econometric Reviews (forthcoming).

Decancq, K., And E. Ooghe (2010): "Has the world moved forward? A robust multidimensional evaluation," Economics Letters, 107(2), 266-269.

Dowrick, S., AND M. Akmal (2005): "Contradictory trends in global income inequality: a tale of two biases.," Review of Income and Wealth, 51(2), 201-229.

EAsterlin, R. (2000): "The worldwide standard of living since 1800," Journal of Economic Perspectives, 14(1), 7-26.

Gajdos, T., And J. A. Weymark (2005): "Multidimensional generalized Gini indices," Economic Theory, 26(3), 471-496.

Herrero, C., R. Martínez, and A. Villar (2010): "Multidimensional social evaluation: an application to the measurement of human development," Review of Income and Wealth, 56(3), 483-497.

Hicks, D. A. (1997): "The inequality-adjusted human development index: A constructive proposal," World Development, 25(8), 1283 - 1298.

Hobijn, B., and P. H. Franses (2001): "Are living standards converging?," Structural Change and Economic Dynamics, 12(2), 171-200. 
Kolm, S.-C. (1977): "Multidimensional egalitarianisms," The Quarterly Journal of Economics, 91(1), 1-13.

Layard, R. (2005): Happiness: Lessons for a new Science. Penguin, London.

Lorzano Segura, S., and E. Gutierrez Moya (2009): "Human Development Index: A non-compensatory assessment," Cuadernos de Economía, 28(50), 222-235.

McGillivray, M. M., and J. Ram Pillarisetti (2004): "International inequality in well-being," Journal of International Development, 16(4), 563-574.

McMichael, A. J., M. McKee, V. Shkolnikov, and T. Valkonen (2004): "Mortality trends and setbacks: global convergence or divergence?," Lancet, 363(9415), $1155-1159$.

Milanovic, B. (2002): "True world income distribution, 1988 and 1993: first calculation based on household surveys alone," The Economic Journal, 112(476), 51-92.

(2005): Worlds apart: Measuring International and Global Inequality. Princeton University Press, Princeton.

Moser, K., V. Shkolnikov, and D. Leon (2005): "World mortality 1950-2000: divergence replaces convergence from the late 1980s," Bulletin of the World Health Organization, 83(3), 202-208.

Muller, C., And A. Trannoy (2011): "A dominance approach to the appraisal of the distribution of well-being across countries," Journal of Public Economics, 95(3-4), 239 -246 .

Neumayer, E. (2003): "Beyond income: convergence in living standards, big time," Structural Change and Economic Dynamics, 14(3), 275-296.

Noorbakhsh, F. (2007): "International convergence or higher inequality in human development? Evidence for 1975-2002," in Advancing Development: Core Themes in Global Economics, ed. by G. Mavrotas, and T. Shorrocks, pp. 149-167. Palgrave Macmillan, Basingstoke, New York.

Nussbaum, M. (2000): Women and Human Development. Cambridge University Press, Cambridge.

Pinkovskiy, M., and X. Sala-I-Martin (2009): "Parametric Estimations of the World Distribution of Income," Working Paper 15433, National Bureau of Economic Research.

Pogge, T. (2009): "Developing morally plausible indices of poverty and gender equity: A research program," Philosophical Topics, 37(2), 199 Ü221. 
Ravallion, M. (2010a): "Mashup Indices of Development," World Bank Policy Research Working Paper No. 5432.

(2010b): "Troubling Tradeoffs in the Human Development Index," World Bank Policy Research Working Paper No. 5484.

(2011): "On multidimensional indices of poverty," Journal of Economic Inequality, pp. 1-14, 10.1007/s10888-011-9173-4.

Rawls, J. (1971): A Theory of Justice. Belknap Press of Harvard University Press, Cambridge, Mass.

Sala-I-Martin, X. (2006): "The world distribution of income: falling poverty and ... convergence, period.," The Quarterly Journal of Economics, 121(2), 351-397.

Sen, A. K. (1985): Commodities and Capabilities. North-Holland, Amsterdam and Oxford.

Slottje, D. J., G. Scully, J. Hirschberg, and K. J. Hayes (1991): Measuring the Quality of Life across Countries. Westview Press.

Stiglitz, J. E., A. Sen, And J.-P. Fitoussi (2009): "Report by the Commission on the measurement of economic performance and social progress," Mimeo.

The EConomist (2003): "Catching up. If you consider people, not countries, global inequality is falling rapidly," .

United Nations Development Programme (2005): "Human Development Report 2005," Oxford University Press, New York.

(2010): "Human Development Report 2010," Oxford University Press, New York.

Weymark, J. A. (1981): "Generalized Gini inequality indices," Mathematical Social Sciences, 1(4), 409-430.

(2006): "The normative approach to the measurement of multidimensional inequality," in Inequality and economic integration, ed. by F. Farina, and E. Savaglio. Routledge, London.

Wolff, H., H. Chong, and M. Auffhammer (2010): "Classification, detection and consequences of data error: Evidence from the human development index," Working Paper 16572, National Bureau of Economic Research.

World BAnk (2005): World Development Report 2006: Equity and Development. World Bank Publications, Washington D.C. 